\title{
Land abandonment under rural restructuring in China explained from a cost-benefit perspective
}

\author{
Ying Zhang a , Xiubin Li ${ }^{\mathrm{b},}{ }^{*}$, Wei Song ${ }^{\mathrm{b}}$, Liang Zhai ${ }^{\mathrm{a}}$ \\ a Chinese Academy of Surveying \& Mapping, 28 Lianhuachi West Road, Haidian District, Beijing, 100830, China \\ ${ }^{\mathrm{b}}$ Key Laboratory of Land Surface Pattern and Simulation, Institute of Geographic Sciences and Natural Resources Research, Chinese Academy of Sciences, \\ 11A, Datun Road, Chaoyang District, Beijing, 100101, China
}

\section{A R T I C L E I N F O}

\section{Article history:}

Received 25 September 2015

Received in revised form

21 June 2016

Accepted 28 June 2016

Available online 25 July 2016

\section{Keywords:}

Land abandonment

Land quality

Farm household distance

Agricultural profit

\begin{abstract}
A B S T R A C T
China has experienced socio-economic transitions in recent decades, featuring a large amount of rural labor migrating into urban areas. As a response, rural land use has been restructured across large areas. In this process, vast amounts of land have been abandoned due to labor loss, especially in mountainous areas. Understanding how land attributes determine which land parcels are abandoned is essential to sustainable development of rural areas. Here we examine how two main farmland parcel attributes, farmland-to-housing distance and land quality, by affecting farming costs and benefits, and thereby profits, determine farmland abandonment. We constructed a semi-empirical crop profit model based on output benefits and input costs derived from household survey data from mountainous Wulong County, Chongqing Province, China. With this model, crop profits can be estimated and in turn the farmland-tohousing distances at which farming profits diminish to zero ("zero profit distance", abbreviated as "ZPD") can be identified. Based on the hypothesis that land will be abandoned when cultivation cannot make profits, ZPD values can be used to predict patterns of abandonment. At current price levels, the ZPD values are $5.94 \mathrm{~km}, 3.84 \mathrm{~km}, 2.52 \mathrm{~km}$ and $1.48 \mathrm{~km}$ for first-class, second-class, third-class and fourthclass land, respectively. Overall, the observed occurrence of land abandonment in relation to farmland-to-housing distance and land quality is concordant with the model's predictions, supporting the underlying hypothesis that land will be abandoned when the farmland-to-housing distance exceeds the ZPD. These findings may serve as an important tool for predicting land abandonment and identifying countermeasures for mountainous areas.
\end{abstract}

() 2016 Published by Elsevier Ltd.

\section{Introduction}

According to MacDonald et al. (2000) and Strijker (2005), land abandonment is often related to rural depopulation and the rise of rural labor opportunity cost. China has experienced rapid and farreaching transitions since Deng Xiaoping launched economic reforms in 1978, with GDP increasing nearly $8 \%$ annually. As China has evolved into a majority urban country, a large amount of rural labor has migrated into urban areas to seek better work, education and standards of living (Tao Yang, 1997; De Brauw et al., 2002; Zhang and Song, 2003; Song and Pijanowski, 2014). A shortage of rural labor is becoming a limiting factor for agricultural activities (Chen et al., 2009) and therefore a great challenge to rural areas and

\footnotetext{
* Corresponding author

E-mail address: lixb@igsnrr.ac.cn (X. Li).
}

agricultural production (Woods, 2005, 2012; Long et al., 2011, 2012, 2016; Long, 2014; Song and Liu, 2014). Faced with this challenge, rural restructuring has occurred, of which farmland restructuring is a main component. In farmland restructuring, crop production becomes increasingly concentrated on high-quality land, whereas marginal land is abandoned (van Dijk et al., 2005; Rudel et al., 2005; Sanz et al., 2013).

Land abandonment accompanying rural land restructuring has been observed worldwide in recent decades (Baldock et al., 1996; van Dijk et al., 2005; Gellrich et al., 2007a; MacDonald et al., 2000), especially in developed countries. Thus, land abandonment has featured prominently in Europe, North America and Japan (Caraveli, 2000; Rudel et al., 2005; Sluiter and De Jong, 2007). In Europe, in particular, extensive research has recently been done on land abandonment and ecological recovery in areas such as the south of France (Sanz et al., 2013), Portugal (van Doorn and Bakker, 2007), Switzerland (Price et al., 2015), and Austria (Silber and 
Wytrzens, 2006); it has also been studied in the Mediterranean area in general (Weissteiner et al., 2011). Land abandonment has also been occurring in developing countries including China (Liu and Li, 2006). As well as Chile (Díaz et al., 2011) and Argentina (Izquierdo and Grau, 2009).

Although no official data have been released regarding the amount of land abandoned in China, some research has been done on the severity of land abandonment (Dong et al., 2011). In particular, a literature review revealed reports of land abandonment from 26 provinces (about 2/3 of the total) (Liu and Li, 2006). Moreover, by interpreting remote sensing images, our research group has found that about $15 \%$ of land was abandoned in south China between 2003 and 2013 (Li et al., 2014).

Much research has been done on the forces driving land abandonment throughout the world, and has found it to happen often in areas where farming faces particular challenges. Thus, land abandonment has often occurred in mountainous areas where labor losses could not easily be replaced by the use of machinery (MacDonald et al., 2000). Examples of this phenomenon are widespread, coming from Swiss mountains (Gellrich et al., 2007b; Gellrich and Zimmermann, 2007), the Alps (Gellrich et al., 2008; Walther, 1986; Gehrig-Fasel et al., 2007), the Pyrenees (Mottet et al., 2006), and the Ecuadorian Andes (Harden, 1996). In addition to steep slope (Gellrich and Zimmermann, 2007), other factors leading to abandonment include poor soil (Sluiter and De Jong, 2007; Díaz et al., 2011) and difficult road access (Gellrich et al., 2007b). The basic driver underlying land abandonment is a change in the relative prices of inputs and outputs (Strijker, 2005).

Nevertheless, there has been little work done to develop models that can quantitatively relate land abandonment to land attributes. In the present study, we develop a model, parameterize it with actual data, and then test it by comparing predicted and observed patterns of land abandonment. This research builds upon a previous study (Zhang et al., 2014) that showed that land quality and farmland distance to the homestead (henceforth referred to as "land distance") are the most important factors influence land abandonment in Wulong County (Chongqing Municipality), a mountainous area of China.

Here we develop and test a cost-benefit model based on the hypothesis that land will be abandoned when it is not profitable to grow crops there. This model was designed to predict patterns of land abandonment based on land quality rankings, land distance data, and crop information. Like our previous study (Zhang et al., 2014), the present one takes advantage of abundant first-hand data collected through surveys of numerous households in the study area from 2011 to 2013.

\section{Materials and methods}

\subsection{Description of the investigated field sites and data collection}

The study area is located in Wulong County (Fig. 1) in southwestern China. In this county, $70-80 \%$ of the total area is mountainous and covered by forest, with the remaining area used for agriculture and construction. According to the statistical data issued by the Statistical Bureau of Wulong County $(2001,2010)$, this county has experienced great labor loss since 2001. Through the end of 2009 , rural labor had diminished by nearly $20 \%$ compared to 2001 . Over the same period, nearly $10 \%$ of cropland was abandoned. The climate supports a two- or three-crop rotation system, but farmers are restricted to single crop rotation due to a lack of labor.

A total of four villages were selected for investigation: Eguan, Qianjin, Dongsheng and Chepan, which are located on mountainsides in Wulong county (see Fig. 1.). The elevation varies from $267 \mathrm{~m}$ to $1920 \mathrm{~m}$, with much of land in these four villages being very steep. According to the land use map supplied by the local government, cropland accounts for $22.17 \%$ of the total land in the four villages, with a higher proportion in Eguan and Qianjin than in Dongsheng and Chepan (Fig. 1).

The four villages have experienced major rural-urban labor migration, with some land abandoned due to lack of labor. For a household with young labor, the main income always comes from payment for off-farm work. However, agricultural income is a major part of the income for households without young labor. In these villages, the market is well-developed, and thus villagers can buy or sell agricultural products in the market. However, there is a very limited market for low-wage agricultural laborers.

Due to the steep terrain in these four villages, traffic conditions are very poor. Farmers commute between land parcels and their houses on foot and carry their products in pack baskets. The main crops for this area are maize, rice, sweet potato, potato, and some cash crops such as tobacco. Sweet potato and potato are always interplanted with maize, which is the most common crop, accounting for almost half the cropland. Owing to strict planting requirements for rice and tobacco, with paddy rice needing to be close to water resource and tobacco suitable for planting only at elevations between $1000 \mathrm{~m}$ and $1200 \mathrm{~m}$, they are excluded from this analysis. This leaves the three other main crops and their combinations: maize, sweet potato, potato, maize-sweet potato, maize-potato, and maize-sweet potato-potato.

The main data source was our first-hand data collected by a household survey conducted in 2012 using a semi-structured questionnaire. About 80 households were randomly selected for surveying in each of the four studied villages. In all, the survey covered 307 households and 2433 land parcels. The total area of cropland involved was 136.2 ha. Each household owns about ten parcels of land, each with an average area less than 0.06 ha.

The questionnaire's responses provided abundant information on the households and associated land parcels. For each household, information was collected on each member, including his or her age, gender, amount of time devoted to agricultural work and offfarm work, and income. For all land parcels associated with each household, including parcels they owned (whether cultivated by them, abandoned or rented out to others for cultivation) or that they rented from others (for cultivation), we recorded attributes including land slope, land quality, and distance to residence. The land quality information was taken from local-government-issued land-use certificates, which classified land quality into four ranks based on their output capacity: first class, second class, third class and fourth class, with first class land having the highest output capacity and fourth class the lowest. Additionally, management characteristics for each parcel, including capital and labor inputs, as well as agricultural product outputs were recorded.

\subsection{Crop profit calculation and main variable estimation}

Crop profit from cultivation is the net income after costs are subtracted from sales revenue generated by agricultural product market sales. The costs include capital costs and labor costs. Capital costs include expenditures for seeds, fertilizer, pesticides, herbicides, and other materials, while labor cost represents the total amount of time put into the cultivation and harvesting of crops, multiplied by the wage for that labor. Thus,

$R_{i}=P_{i}^{*} Q_{i}-C_{x i}-W^{*} L_{i}$

where $R_{i}$ is the profit from cultivation when planting crop $i, P_{i}$ is the sale price of crop $i, Q_{i}$ is the production of crop $i, C_{x i}$ and $L_{i}$ are, respectively, the capital input and labor input (in days) for crop $i$, and $W$ is the (daily) labor wage. 


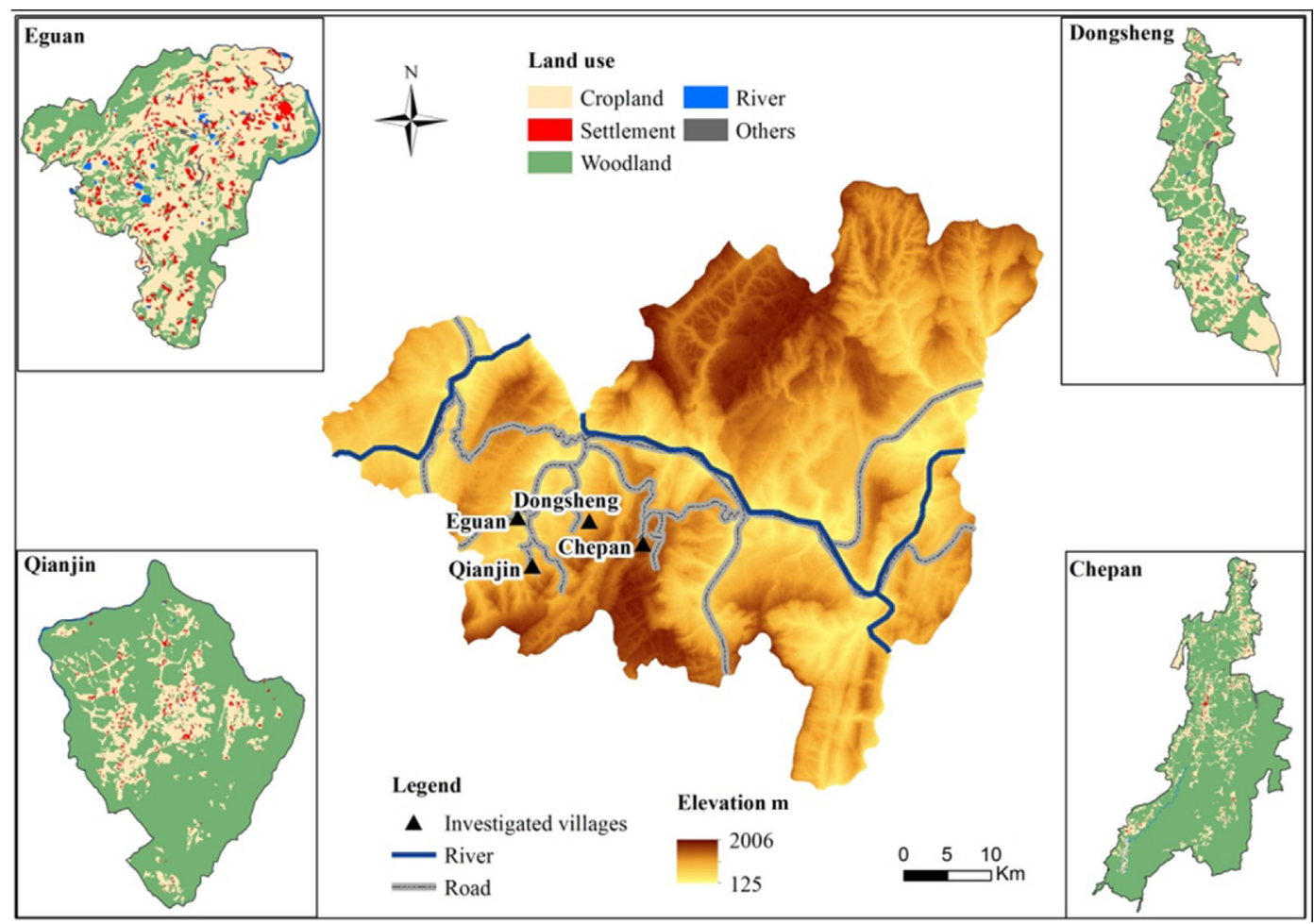

Fig. 1. Locations, topography and land use of the studied villages in Wulong County.

During the study, we found that the inputs per unit of land did not show significant differences across the land parcels of the same land quality rank that had the same crop. Therefore, we can assume no variation in crop-specific input per unit of land across different parcels with the same land quality rank, either in labor input for cultivation or in capital input. Thus, the variation in crop yield was attributable mainly to differences in land quality, and crop yield can therefore be expressed as a function of land quality.

In order to analyze the impact of land distance on labor cost, we divided labor input into three parts: time cost for cultivation, time cost for commuting, and time cost for transporting products. Time cost for cultivation is the effective time in the field devoted to growing the crops, which directly affects the production. Commuting time is the time cost for traveling between home and the land parcels, whereas transporting time is the time cost for harvesting the crops and transporting them home. Increased time spent commuting and transporting does not contribute to increased production. However, all of the time costs are necessary for producing and harvesting the crops. The commuting time cost is a function of land distance, and transporting time cost is a function of land distance and the weight of outputs.

Therefore, the profit per unit of land in Equation (1) can be specified as:

$R_{i}=P_{i} * Q_{i}\left(l_{q}\right)-C_{x i}\left(l_{q}\right)-W * T_{p i}-W * T_{d}(d)-W * T_{h}\left(Q_{i}\left(l_{q}\right), d\right)$

In Equation (2), each variable is measured per unit of land, with the subscript $i$ representing the crop type; $R_{i}$ the net profit per hectare (Unit: RMB/ha), $P_{i}$ the average sale price per kilogram of crop $i$ (Unit: RMB $/ \mathrm{kg}$ ), $Q_{i}$ the yield of crop $i$ (Unit: $\mathrm{kg} / \mathrm{ha}$ ), which is a function of land quality $\left(l_{q}\right), C_{x i}$ the capital input per hectare (Unit: $\mathrm{RMB} / \mathrm{ha}$ ), which is a function of land quality $\left(l_{q}\right), W$ the (daily) labor wage (Unit: $\mathrm{RMB} / \mathrm{day}), T_{p i}$ field time input for raising the crop (Unit: days), $T_{d}(d)$ the commuting time cost (Unit: days), $d$ the distance from home to the land parcel (Unit: kilometers); and $T_{h}$ the transporting time cost (Unit: days), which is a function of distance $d$ and yield $Q_{i}\left(l_{q}\right)$.

\subsubsection{The determination of sales prices, capital inputs and crop yields}

The average sales prices for maize, potato and sweet potato were recorded in the study as $2 \mathrm{RMB}, 1 \mathrm{RMB}$ and $0.7 \mathrm{RMB}$ per kilogram, respectively. As mentioned above, the crop-specific capital input per unit of land is assumed to be the same across different parcels with the same land quality rank. Therefore, for each crop, we averaged the crop-specific capital input across all the land parcels of the same quality. Similarly, we obtained average-yields for each crop for each land quality rank. Based on the survey data, the averages for capital inputs and crop yields for each land quality rank are listed in Table 1 and Table 2.

\subsubsection{Time-cost estimation}

Commuting time cost is calculated by multiplication of the traveling time cost for a one-way trip by the number of times that trip must be made. The one-way trip traveling-time cost is a function of land distance $d$ without consideration of differences in elevation. Our data revealed that traveling one kilometer takes about 15.38 min on average, so the variable $T(1)$ can be expressed as Equation (3)

$$
T(1)=15.38 /(60 * 8) * d
$$

in which 15.38 represents the time in minutes it takes to travel one kilometer, $60 * 8$ represents 60 min per hour times the 8 working hours per day, $T(1)$ is the one-way traveling time cost, and $d$ is the distance from the homestead to the specific land parcel. In our study areas, farmers have to go home for lunch, thus they need to travel four times per working day. Therefore, the total commuting time cost can be expressed as Equation (4) 
Table 1

The average capital inputs of main crops for each quality class of land (unit: RMB/ha).

\begin{tabular}{|c|c|c|c|c|c|c|}
\hline Land quality & Maize & Sweet potato & Potato & Maize-sweet potato & Maize-potato & Maize-sweet potato-potato \\
\hline First class & 3646.26 & 1802.18 & 8250.00 & 6268.87 & 7832.59 & 11762.58 \\
\hline Second class & 3704.63 & 4406.42 & 7390.00 & 6180.18 & 9177.24 & 12057.92 \\
\hline Third class & 3868.37 & 3881.35 & 3807.55 & 5914.77 & 8117.07 & 12504.22 \\
\hline Fourth class & 3551.07 & 2993.70 & 4899.13 & 6083.75 & 7446.59 & 11584.97 \\
\hline
\end{tabular}

Notes: The inputs in this table include seed cost, fertilizer cost, plastic film and other costs needed to be paid directly. However, they do not include labor cost.

Table 2

The average crop yields of main crops for each quality class of land (unit: kg/ha).

\begin{tabular}{|c|c|c|c|c|c|c|}
\hline Land quality & Maize & Sweet potato & Potato & Maize-sweet potato & Maize-potato & Maize-sweet potato-potato \\
\hline First class & 5500.18 & 20787.88 & 12187.50 & 21214.79 & 14818.86 & 28739.42 \\
\hline Second class & 4669.05 & 18589.17 & 12037.50 & 20273.08 & 15236.06 & 30643.42 \\
\hline Third class & 4553.85 & 18352.68 & 10684.10 & 18412.12 & 13409.96 & 28313.18 \\
\hline Fourth class & 3751.75 & 16153.88 & 9862.20 & 14383.80 & 12034.20 & 21063.03 \\
\hline
\end{tabular}

$T_{d}(d)=T(1) * t(c)=4 * T(1) * T_{p i}$

in which $T_{d}(d)$ is the total commuting time cost, $t(c)$ the number of one-way trips per working day, and $T_{p i}$ is the total number of working days spent per year for cultivation (which excludes harvest) for crop $i$.

Each transport of crops requires a round trip, as farmers have to travel back and forth between the land and their home. For simplification, we assumed transporting time cost is the same as the traveling time cost for a given distance. Thus, the time cost for a transporting round-trip is twice that of the one-way traveling time cost. In mountainous areas, transportation is major physical work. Farmers have to transport their agricultural products on foot by pack basket, and our survey revealed that each healthy adult can carry on average only $40 \mathrm{~kg}$ at a time. Therefore, the frequency of transportation journeys is the output of crops divided by 40 . The total transportation time cost is specified as Equation (5)

$T_{h}\left(Q_{i}\left(l_{q}\right), d\right)=2 * T(1) * t(h)=2 * T(1) * Q_{i}\left(l_{q}\right) / 40$

in which $T_{h}\left(Q_{i}\left(l_{q}\right), d\right)$ the total time cost for transportation, $t(h)$ is the number of (one-way) trips for transportation, and $Q_{i}\left(l_{q}\right)$ the production of crop $i$ when planted on land with quality $l_{q}$.

\subsubsection{Labor wage estimation}

Due to little access to the market, agricultural labor wages cannot be measured in the market directly. A 'shadow wage' is an effective method to estimate labor payments when the labor market is imperfect, and is defined as the marginal increase of income due to an increase of one unit of labor (Jacoby, 1993). The labor payment is an elastic component of agricultural income and can be estimated from the production function specified in the following equation.

$\ln G=\alpha \operatorname{Ln} A+\beta \operatorname{Ln} C+\gamma \operatorname{Ln} L$

in which $A, C$ and $L$ are three basic inputs corresponding to land area, capital input, and labor input, respectively. $\alpha, \beta$ and $\gamma$ are the elastic coefficients of crop production, to be estimated.

When the parameter $\gamma$ is obtained, we can easily find the labor 'cost' through Equation (7), and then the wage will be the labor cost divided by labor input, using Equation (8), as follows.
$I=\frac{\partial G}{\partial L}=\gamma \times G$

$w=I / L$

Usually, agricultural production is a collective activity, and the cost of labor cannot be allocated to each laborer, so the production model should include all product income and labor input. In this model, the sales prices of all the main crop products, including maize, rice, sweet potato and potato, are aggregated together as the output value. The variables employed and the estimated results using an ordinary least squares model are listed in Table 3. The results show that the model fits well $\left(R^{2}=0.660\right)$. The agricultural income elasticity of labor input is 0.322 , which is close to Wang's result (0.3146) from the Zhejiang case study (Wang et al., 2007). Using this elasticity, we can get the labor payment from production activity and the labor wage for each family. Our model indicates an average value of $19.21 \mathrm{RMB} /$ day as the labor wage, which we then use for crop profit calculation.

\subsection{Theoretical hypothesis and its validation}

According to ground rent theory and rational peasant theory, a household will stop cultivation when this activity cannot make profits. That is, if net profit from cultivation is above zero, it will continue on the land. Otherwise, land will be abandoned, which is represented as follows:

$y= \begin{cases}1 & \text { if } \max \left(R_{i}\right) \leq 0 \\ 0 & \text { if } \max \left(R_{i}\right)>0\end{cases}$

where $R_{i}$ is the net profit from crop $i$, while $y$ is the land-use decision, with value " 1 " representing land abandonment and value "0" representing continued agriculture.

According to this theoretical framework, land will be abandoned when it cannot make profits for any crop planting. That is, any parcel with land distance equal to or farther than its zero profit distance will be abandoned. Otherwise, land will be kept in agricultural use. Therefore, the land areas subjected to abandonment can be predicted based on the zero profit distance and the classification of land parcels in terms of land distance and quality. In order to validate the theoretical hypothesis, we compared the land abandonment occurrence it predicted with observed occurrence. To make this comparison, we calculated land abandonment rates for the study area as a whole as well as for land classified according to 
Table 3

The variables and estimated results of the agricultural income function based on the OLS model.

\begin{tabular}{|c|c|c|c|}
\hline Variable & Unit & Coefficient & t-value \\
\hline (constant) & - & $5.893^{* *}$ & 9.992 \\
\hline Log (labor input) & Days & $0.322^{* *}$ & 4.377 \\
\hline $\log ($ area $)$ & $\mathrm{mu}$ & $0.511^{* *}$ & 7.671 \\
\hline Log (fertilizer cost) & RMB & $0.039^{* *}$ & 0.378 \\
\hline Log (pesticide cost) & RMB & 0.143 & 2.967 \\
\hline $\log ($ mulch cost) & RMB & -0.02 & -0.39 \\
\hline Land quality class & Grade & $0.128^{*}$ & -2.318 \\
\hline Proportion of male laborers & $\%$ & $0.178^{* *}$ & 2.666 \\
\hline Proportion of female laborers & $\%$ & 0.015 & 0.278 \\
\hline Average age of agricultural laborers & Years old & $-0.042^{* *}$ & -3.429 \\
\hline Squared average age & Square years old & $0.000^{* *}$ & 3.164 \\
\hline Proportion of laborers with primary school education & $\%$ & 0.065 & 0.511 \\
\hline Proportion of laborers with middle school education & $\%$ & 0.154 & 1.13 \\
\hline Proportion of laborers with high school education & $\%$ & -0.032 & -0.158 \\
\hline Proportion of laborers with college education & $\%$ & -0.003 & -0.007 \\
\hline $\mathrm{R}^{2}$ & - & 0.660 & - \\
\hline
\end{tabular}

Note: ${ }^{*}$ and ${ }^{* *}$ represent $5 \%$ and $1 \%$ statistical significance, respectively.

its land distance and quality, using the following formula

$k=A_{b} / A^{*} 100 \%$

where $A_{b}$ is the area of abandoned land, and $A$ is the total agricultural land area (in-use plus abandoned).

\section{Results}

\subsection{Abandonment as related to land quality and distance}

About $80 \%$ of our total studied cropland of area 136.2 ha was of medium land quality (second class or the third class), whereas the first class and the fourth class cropland accounted for only $9.25 \%$ and $13.66 \%$ of the total, respectively (Fig. 2).

The land-use map (Fig. 1) shows cropland to usually be located around the rural settlements, with the distance between the center of cropland parcels and the nearest rural settlements about $800 \mathrm{~m}$ on average, without considering land parcel ownership. Moreover, our investigation found that cropland area decreased with increasing distance from the settlements where the land owners resided (i.e., land distance). Thus, about $65.79 \%$ of the total land was located at a radius of $1.0 \mathrm{~km}$ around the rural settlements in which the owners lived, while $25.04 \%$ of the total land had a land distance between $1.0 \mathrm{~km}$ and $2.0 \mathrm{~km}$. Less than $10 \%$ of land had a land distance farther than $2.0 \mathrm{~km}$ (Fig. 2).

The total area of abandoned land in our study area was 19.86 ha, yielding an abandonment rate of $14.58 \%$. The fourth class land showed the highest probability of land abandonment, with an

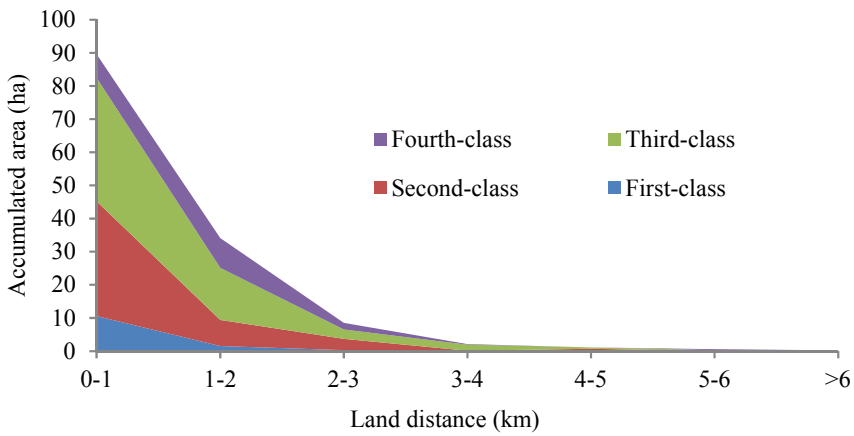

Fig. 2. Cropland area distribution for each combination of land quality rank and land distance. abandonment rate of $46.25 \%$, while the third class land abandonment rate was $13.96 \%$. The abandonment rates were progressively lower on second class land and first class land, as they were only $5.74 \%$ and $3.38 \%$, respectively. Therefore, we found higher probability of land abandonment on poorer quality land.

Land abandonment rates showed an increasing trend with land distance, with land abandonment having a low frequency for land near a settlement. If the land distance was less than $1.0 \mathrm{~km}$, the observed land abandonment rate was only $6.39 \%$, but the rate increased to $21.55 \%$ when the land distance was between $1.0 \mathrm{~km}$ and $2.0 \mathrm{~km}$. The rate increased to $46.87 \%, 52.86 \%$, and $81.82 \%$ when land distances were around $3.0 \mathrm{~km}, 4.0 \mathrm{~km}$ and $5.0 \mathrm{~km}$, respectively. When the land distance was farther than $6 \mathrm{~km}$, all land would be abandoned.

\subsection{Crop profits and zero profit distances}

For any land parcel with any land distance and any land-quality rank, its crop-specific profit could be calculated based on the crop profit model. The average profits in relation to land distance for the main crops grown on the different quality land parcels are shown in Fig. 3.

The crop profits declined with increasing distance because as the land distance increases labor costs for commuting and transporting increase. Although all the average crop profits showed decreasing trends in relationship to increasing land distance, the rates of decrease, i.e., slopes, differed statistically significantly among the crops (see Fig. 3). Usually, the gradient was steeper for heavy crops than for light ones because heavy crops need more transportation time than light ones from the same land parcel. Among all the crops, maize had the shallowest gradient, with its net profit declining most slowly. Thus, maize cultivation can allow for the greatest land distance for any given land quality rank. This likely explains why maize is the most common crop in the study area, with its area accounting for nearly half the cultivated land. Of the other crops and their combinations, the profit for sweet potato declined faster than others on the first class land, second class land and third class land, whereas the profits for the three crop combinations declined fastest on the fourth class land.

Crop profit also varied with land-quality rank. Generally, for a given land distance, crop profits are higher on the higher quality rank land. This is because a higher quality rank means greater production, which yields higher income, and therefore higher profit. In Fig. 3, for a given land distance, each crop shows a higher profit in Panel "a" than in any of the other panels. For example, 

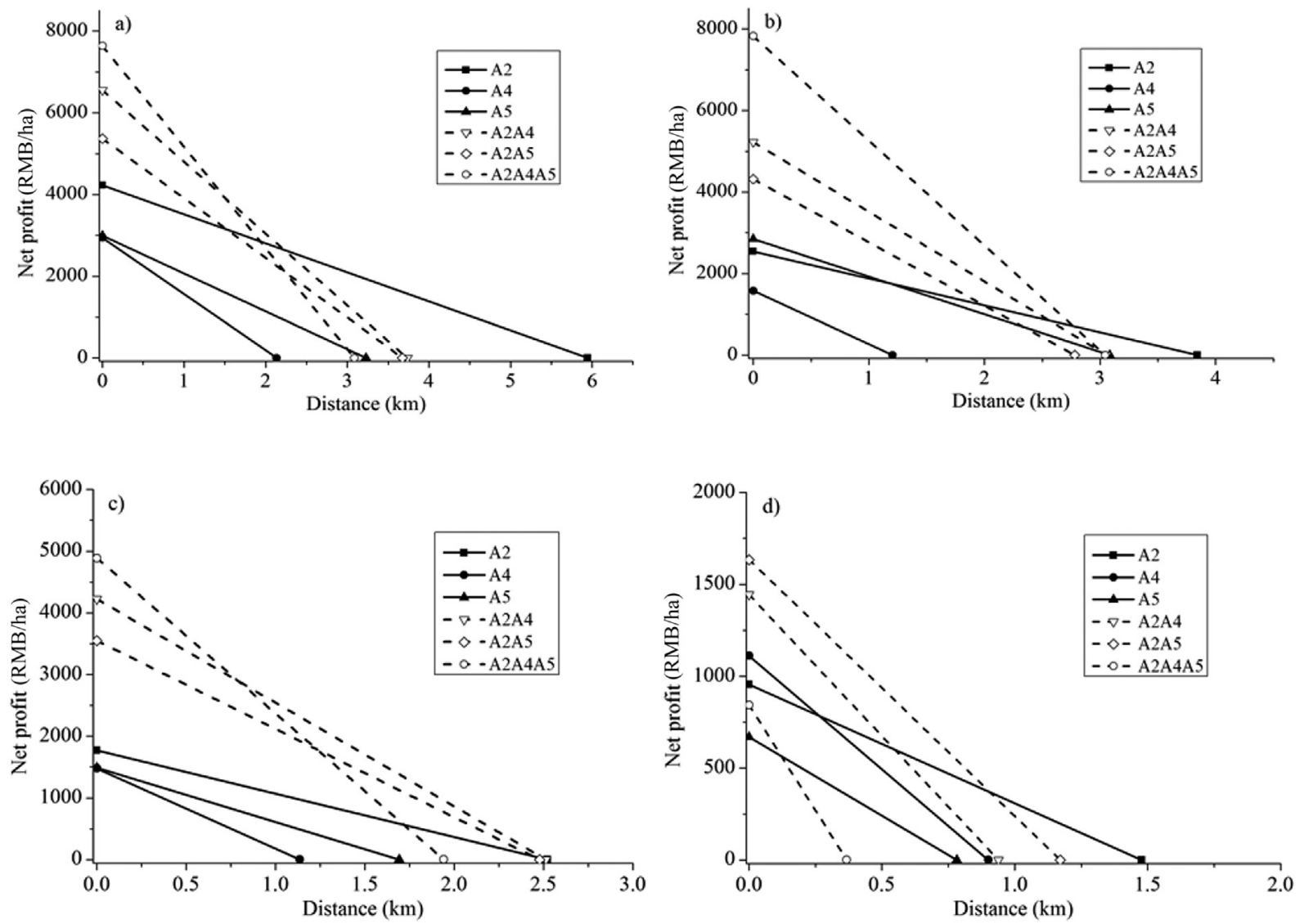

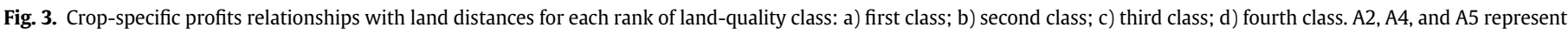

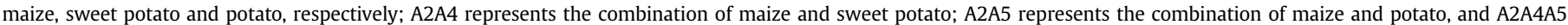
represent the combinations of maize, sweet potato and potato.

maize had a profit of zero when the land distance was near $6 \mathrm{~km}$ on the first-class land, but its profits were exclusively below zero on the other three classes of land.

For any given crop, when the land distance reaches the value where crop profit declines to zero, there is no incentive to raise that crop. However, other crops may still yield profits at that distance, and agricultural activity will continue if there is at least one crop that can yield a profit. As land distance continues to increase, crop profits for other crops will continue to decease. When land distance increases to a certain distance where profits for raising any crop are below or equal to zero, cultivation cannot be profitable; we call this distance the zero profit distance (ZPD).

In this study area, although maize did not have the highest profit at any distance, it did have the greatest ZPD. For first class land, when land distance increased to $5.94 \mathrm{~km}$, the profit declined to zero or below zero for all crops. Similarly, there was no crop that could render a profit at the distances of $3.84 \mathrm{~km}, 2.52 \mathrm{~km}$ and $1.48 \mathrm{~km}$ for second class, third class and fourth class land, respectively (Fig. 3).

\subsection{Predicted land abandonment and its comparison with observations}

Our model indicated that all parcels with land distance less than $1.48 \mathrm{~km}$ would be kept in agricultural use; for parcels with land distances between $1.48 \mathrm{~km}$ and $2.52 \mathrm{~km}$, only the fourth class land would be abandoned; for parcels with land distances greater than $2.52 \mathrm{~km}$ but less than $3.84 \mathrm{~km}$, all the third class and fourth class land would be abandoned; parcels with land distances between
$3.84 \mathrm{~km}$ and $5.94 \mathrm{~km}$, would all be abandoned with the exception of first class land; and parcels with land distance greater than $5.94 \mathrm{~km}$ would be entirely abandoned.

These predictions in turn yielded specific predictions of total abandoned cropland area (in ha) for the study area as a whole and for each of the study area's parcels as categorized by land quality and land distance (see Fig. 2). We then compared the predicted and observed abandonment areas, as shown in Table 4.

Of the total investigated land area, 17.22 ha were predicted to have been abandoned, which is close to the observed abandoned area of 19.86 ha. Thus, $86.68 \%$ of the observed abandoned land area was correctly predicted. Although this prediction was not completely consistent with the observed results for each land quality rank and distance interval, the tendency was for the predicted and observed areas to be in overall accord.

Of the predicted abandoned land, the fourth class land was predicted to be abandoned most, accounting for $66.86 \%$ of the total predicted abandoned land. There were 5.2 ha of third class land predicted to be abandoned, accounting for $30.23 \%$ of the total predicted abandoned land. In fact, most of the observed abandoned land was fourth class land and third class land, accounting for $41.11 \%$ and $43.28 \%$ of the total observed abandoned land, respectively.

Regarding responses to land distance, when it was greater than $4 \mathrm{~km}$, the predicted and observed abandonment areas for each land quality rank were completely consistent with each other (see Table 4). Moreover, the observed and predicted areas were roughly equal to each other for land distances between $1-2 \mathrm{~km}$ and 
Table 4

The predicted and observed land abandonment areas for each land quality class and distance interval (ha).

\begin{tabular}{|c|c|c|c|c|c|c|c|c|c|c|c|c|c|c|c|}
\hline \multirow[t]{3}{*}{ Land qualit } & & \multicolumn{14}{|c|}{ Land distance } \\
\hline & & \multicolumn{2}{|c|}{$0-1 \mathrm{~km}$} & \multicolumn{2}{|c|}{$1-2 \mathrm{~km}$} & \multicolumn{2}{|c|}{$2-3 \mathrm{~km}$} & \multicolumn{2}{|c|}{$3-4 \mathrm{~km}$} & \multicolumn{2}{|c|}{$4-5 \mathrm{~km}$} & \multicolumn{2}{|c|}{$5-6 \mathrm{~km}$} & \multicolumn{2}{|c|}{$>6 \mathrm{~km}$} \\
\hline & & Pre & Obs & Pre & Obs & Pre & Obs & Pre & Obs & Pre & Obs & Pre & Obs & Pre & Obs \\
\hline \multirow[t]{2}{*}{1 st class } & A & 0 & 0.43 & 0 & 0 & 0 & 0 & 0 & 0 & 0 & 0 & 0 & 0 & 0 & 0 \\
\hline & $\mathrm{P}$ & 0 & 0.48 & 0 & 0 & 0 & 0 & 0 & 0 & 0 & 0 & 0 & 0 & 0 & 0 \\
\hline \multirow[t]{2}{*}{2 nd class } & A & 0 & 0.31 & 0 & 0.55 & 0 & 1.31 & 0 & 0 & 0.5 & 0.5 & 0 & 0 & 0 & 0 \\
\hline & $\mathrm{P}$ & 0 & 0.35 & 0 & 1.61 & 0 & 15.41 & 0 & 0 & 45.45 & 45.45 & 0 & 0 & 0 & 0 \\
\hline \multirow[t]{2}{*}{ 3rd class } & A & 0 & 2.57 & 0 & 2.33 & 2.50 & 1.26 & 1.80 & 1.11 & 0.40 & 0.40 & 0.30 & 0.30 & 0.20 & 0.20 \\
\hline & $\mathrm{P}$ & 0 & 2.87 & 0 & 6.83 & 29.41 & 14.82 & 85.71 & 52.86 & 36.36 & 36.36 & 50 & 50 & 100 & 100 \\
\hline \multirow[t]{2}{*}{ 4th class } & A & 0 & 2.42 & 9.00 & 4.47 & 2.00 & 1.41 & 0.20 & 0 & 0 & 0 & 0.30 & 0.30 & 0 & 0 \\
\hline & $\mathrm{P}$ & 0 & 2.70 & 26.39 & 13.11 & 23.53 & 16.59 & 9.52 & 0 & 0 & 0 & 50 & 50 & 0 & 0 \\
\hline \multirow[t]{2}{*}{ Tot } & A & 0 & 5.73 & 9.00 & 7.35 & 4.50 & 3.98 & 2.00 & 1.11 & 0.90 & 0.90 & 0.60 & 0.60 & 0.20 & 0.20 \\
\hline & $\mathrm{P}$ & 0 & 6.40 & 26.39 & 21.55 & 52.94 & 46.82 & 95.24 & 52.86 & 81.82 & 81.82 & 100 & 100 & 100 & 100 \\
\hline
\end{tabular}

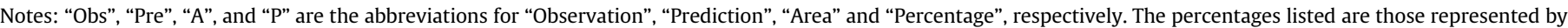
the predicted and observed land abandonment areas of the corresponding total areas.

$2-3 \mathrm{~km}$, with prediction accuracies of $81.66 \%$ and $88.53 \%$ for these two intervals, respectively. However, the prediction was not good for land distances between $0-1 \mathrm{~km}$ and $3-4 \mathrm{~km}$. When the land distance is less than $1 \mathrm{~km}$, the predicted area of land abandonment is zero, whereas the observed land abandonment area was 5.73 ha. For land distance between 3 and $4 \mathrm{~km}, 2.00$ ha of land were predicted to be abandoned, whereas only 1.11 ha were observed to have been abandoned, yielding a prediction accuracy of only $55.50 \%$.

When we compared observed and predicted abandonment rates in terms of percentages of land area abandoned we found strong agreement between them. The difference between predicted and observed abandoned percentages of land area abandoned was less than 10 percentage points at all land distance intervals except for $3-4 \mathrm{~km}$. For land distances $0-0.5 \mathrm{~km}$ and $0.5-1 \mathrm{~km}$, both of the predicted land abandonment rates are $0 \%$, whereas the observed land abandonment rates were $4.6 \%$ and $7.99 \%$, respectively. At the distance interval $1-1.5 \mathrm{~km}$, the predicted and observed rates match, as they both have the value of $12.22 \%$. For the land distance intervals $1.5-2 \mathrm{~km}, 2-2.5 \mathrm{~km}$ and $2.5-3 \mathrm{~km}$, the differences between the two values were $7.57,2.65$ and 5.49 percentage points, respectively. The greatest discrepancy between observed and predicted values was for the interval $3-4 \mathrm{~km}$, with the two values being $49.92 \%$ and $95.07 \%$, respectively. When land distance increased to $4-5 \mathrm{~km}$, the discrepancy between observed and predicted percentages declined to 2.18 percentage points. For land distance greater than $5 \mathrm{~km}$, both the observed and predicted rates were $100 \%$ abandonment. Overall, the prediction fits the observations very well, as both show the same overall trends, with the

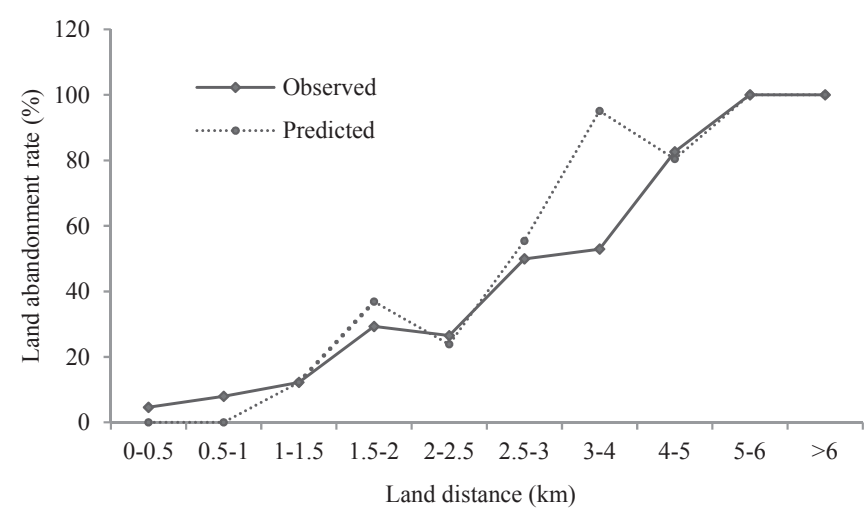

Fig. 4. Comparison between predicted and observed land abandonment rates. single exception of the 3-4 km land distance interval (Fig. 4).

\section{Discussion}

The present study indicated a relationship between land abandonment and decreasing profitability of raising crops such that when cultivation cannot yield profits, land is abandoned. Profits are defined by relative costs and benefits, which in turn are influenced by land parcel attributes. Using first-hand data and a cost-benefit economic model, we examined the influence of land quality and the distance between farmland and homestead on land abandonment, as mediated by the effects of these factors on profits.

The hypothesis that cultivation will cease when it cannot yield profits was supported by this study based on a survey of 334 households. The crop profit curves show that zero profit distances equaled $1.48 \mathrm{~km}, 2.52 \mathrm{~km}, 3.94 \mathrm{~km}$ and $5.94 \mathrm{~km}$ for first class, second class, third class and fourth class land, respectively. Using the inferred profitability of raising crops and the categorization of parcels by land distance and quality to predict land abandonment rates generated an overall predicted rate that is largely in accord with the observed one. This indicates that profitability can explain whether land will be used or be abandoned. Specifically, if there is any crop that yields actual (i.e., positive) profit when taking labor and capital cost into account, that land will be used for agriculture. Otherwise, the land will be abandoned.

Our model explains most of the observed land abandonment, because the predicted land abandonment is close to that observed, although there are still some differences between them. There are at least two possible explanations for these differences. First, the predictions were made based on the zero profit distances of common crops, but there are some cash crops, such as tobacco, whose positive profit can support a greater traveling distance. Second, there may be some factors other than land quality rank and land distance that influence land abandonment. For example, the wild boar population affects land use patterns, but would not be incorporated into the factors that we explored (Hua and Yan, 2015).

Land quality influences crop profits in both positive and negative ways. Because land quality was evaluated in terms of productivity, it unsurprisingly is the key factor associated with differences in crop productivity among different land parcels with comparable labor and capital inputs. Thus, if all else is equal, high quality land will produce much greater outputs than low quality land. On the other hand, higher productivity from high quality land will increase transportation time costs (i.e., labor costs), which can be seen from the steeper gradient of crop profit curves on high quality land than on low quality land (Fig. 3). However, the influence of land quality 
on time cost is less than that on crop productivity, with land quality therefore showing a positive influence on crop profit overall.

Our finding that land quality, which undoubtedly largely reflects soil quality, had a negative effect on land abandonment is in accord with previous findings regarding soil quality proxies such as soil type (Sluiter and De Jong, 2007), soil fertility (van Dijk et al., 2005) and soil stoniness (Gellrich et al., 2007a). All of these have been found to be important factors affecting land abandonment, as poor soil conditions lead to less intensive farming and reduced productivity (van Dijk et al., 2005).

In the system we investigated, because the land parcels are not readily accessible to motor vehicles, land distance to the homestead is crucial for labor cost, as it strongly influences both traveling time cost and transportation time cost, both included in the labor cost. Indeed, since pack baskets are used to carry products home on foot, the distance between farmland and home should be especially important in determining whether farming a particular parcel is a profitable use of time. More generally, when the distance reaches the zero profit distance, rational farmers will stop cultivation. This finding is in accord with the influence of distance to road on land abandonment found in an area where motor vehicles could use main roads (Mottet et al., 2006).

According to MacDonald et al. (2000) and Strijker (2005), land abandonment is often related to rural depopulation and the rise of rural labor opportunity costs. The basic mechanism behind this relationship is a change in the relative prices of inputs and outputs (Strijker, 2005). Our model shows the land abandonment pattern associated with the current prices and labor costs. With continued migration, labor faces a rising opportunity cost, and we can foresee land abandonment becoming much more severe in the future.

\section{Conclusion}

Understanding the process of land abandonment in mountainous regions is important because it is a major aspect of rural restructuring, which will influence future rural landscapes in China. A hypothesis to explain land abandonment is proposed in this paper. In support of it, the results of this case study, as predicted, indicated that land will be abandoned when it cannot make profits. In mountainous areas, the crop profit is influenced mostly by land quality and land distance to the homestead. Land quality mainly influences crop production, whereas land distance affects time cost for traveling (i.e., a labor cost), which ultimately affects crop profit and leads to land abandonment when raising crops cannot yield a profit. The case study also reveals zero profit distances of $5.94 \mathrm{~km}$, $3.84 \mathrm{~km}, 2.52 \mathrm{~km}$ and $1.48 \mathrm{~km}$ for first class, second class, third class and fourth class land, respectively. The observed overall land abandonment rate conforms with that predicted, indicating that land will be abandoned at the zero profit distance. Distance between the farmland and the home can effectively reduce profitability by increasing traveling and transportation costs. Thus, the land abandonment rate grows significantly as distance increases, and when the distance is greater than $6 \mathrm{~km}$, nearly all land will be abandoned. Given its reliability, zero profit distance assessment can be used for prediction of future land use structure and land abandonment. Since land quality and land distance significantly influence the land abandonment rate, we argue that more efforts should be made by local governments to increase the land quality. In addition, it should be made easier to rent agricultural land, as a greater rental market would enable more land to continue to be farmed rather than abandoned.

\section{Acknowledgements}

This study is part of work on the program 'An analysis of the mechanism and decision modeling of land abandonment in hilly areas: a case study of Wushan County, Chongqing', which is financed by National Natural Science Foundation of China (Grant Nos. 41501192 and 41161140352). Additionally, our team members contributed a lot towards collecting household survey data; they are thanked for their effects.

\section{References}

Baldock, D., Beaufoy, G., Brouwer, F., Godeschalk, F., 1996. Farming at the Margins: Abandonment or Redeployment of Agricultural Land in Europe. The Hague, London.

Caraveli, H., 2000. A comparative analysis on intensification and extensification in Mediterranean agriculture: dilemmas for LFAs policy. J. Rural Stud. 16, $231-242$.

Chen, Y.Q., Li, X.B., Tian, Y.J., Tan, M.H., 2009. Structural change of agricultural land use intensity and its regional disparity in China. J. Geogr. Sci. 19, 545-556.

De Brauw, A., Huang, J.K., Rozelle, S., Zhang, L., Zhang, Y., 2002. The evolution of China's rural labor markets during the reforms. J. Comp. Econ. 30, 329-353.

Díaz, G.I., Nahuelhual, L., Echeverría, C., Marín, S., 2011. Drivers of land abandonment in Southern Chile and implications for landscape planning. Landsc. Urban Plan. 99, 207-217.

Dong, J., Liu, J., Yan, H., Tao, F., Kuang, W., 2011. Spatio-temporal pattern and rationality of land reclamation and cropland abandonment in mid-eastern Inner Mongolia of China in 1990-2005. Environ. Monit. Assess. 179, 137-153.

Gehrig-Fasel, J., Guisan, A., Zimmermann, N.E., 2007. Tree line shifts in the Swiss Alps: climate change or land abandonment? J. Veg. Sci. 18, 571-582.

Gellrich, M., Baur, P., Koch, B., Zimmermann, N.E., 2007a. Agricultural land abandonment and natural forest re-growth in the Swiss mountains: a spatially explicit economic analysis. Agric. Ecosyst. Environ. 118, 93-108.

Gellrich, M., Baur, P., Robinson, B.H., Bebi, P., 2008. Combining classification tree analyses with interviews to study why sub-alpine grasslands sometimes revert to forest: a case study from the Swiss Alps. Agric. Syst. 96, 124-138.

Gellrich, M., Baur, P., Zimmermann, N.E., 2007b. Natural forest regrowth as a proxy variable for agricultural land abandonment in the Swiss mountains: a spatial statistical model based on geophysical and socio-economic variables. Environ. Model. Assess. 12, 269-278.

Gellrich, M., Zimmermann, N.E., 2007. Investigating the regional-scale pattern of agricultural land abandonment in the Swiss mountains: a spatial statistical modelling approach. Landsc. Urban Plan. 79, 65-76.

Harden, C.P., 1996. Interrelationships between land abandonment and land degradation: a case from the Ecuadorian Andes. Mt. Res. Dev. 16 (3), 274-280.

Hua, X., Yan, J., 2015. The risk of protection: the dilemma between wildlife protection and cropland use under ecological restoration. GLP Lett. 70-74.

Izquierdo, A.E., Grau, H.R., 2009. Agriculture adjustment, land-use transition and protected areas in Northwestern Argentina. J. Environ. Manag. 90, 858-865.

Jacoby, H.G., 1993. Shadow wages and peasant family labour supply: an econometric application to the Peruvian Sierra. Rev. Econ. Stud. 60, 903-921.

Li, X.B., Tan, M.H., Xin, L.J., 2014. Is it necessary to restart the grain for green project? China Science Daily 2-28.

Liu, C.W., Li, X.B., 2006. Regional differences in the Changes of the agricultural land use in China during 1980-2002. Acta Geogr. Sin. 61 (2), 139-145 (in Chinese).

Long, H.L., 2014. Land consolidation: an indispensable way of spatial restructuring in rural China. J. Geogr. Sci. 24 (2), 211-225.

Long, H.L., Li, Y.R., Liu, Y.S., Woods, M., Zou, J., 2012. Accelerated restructuring in rural China fueled by 'increasing vs. decreasing balance' land-use policy for dealing with hollowed villages. Land Use Policy 29 (1), 11-22.

Long, H.L., Zou, J., Pykett, J., Li, Y.R., 2011. Analysis of rural transformation development in China since the turn of the new millennium. Appl. Geogr. 31 (3), 1094-1105.

Long, H.L., Tu, S.S., Ge, D.Z., Li, T.T., Liu, Y.S., 2016. The allocation and management of critical resources in rural China under restructuring: problems and prospects. J. Rural Stud. http://dx.doi.org/10.1016/j.jrurstud.2016.03.011.

MacDonald, D., Crabtree, J., Wiesinger, G., Dax, T., Stamou, N., Fleury, P., Gutierrez Lazpita, J., Gibon, A., 2000. Agricultural abandonment in mountain areas of Europe: environmental consequences and policy response. J. Environ. Manag. 59, 47-69.

Mottet, A., Ladet, S., Coque, N., Gibon, A., 2006. Agricultural land-use change and its drivers in mountain landscapes: a case study in the Pyrenees. Agr Ecosyst. Environ. 114, 296-310.

Price, B., Kienast, F., Seidl, I., Ginzler, C., Verburg, P.H., Bolliger, J., 2015. Future landscapes of Switzerland: risk areas for urbanisation and land abandonment. Appl. Geogr. 57, 32-41.

Rudel, T.K., Coomes, O.T., Moran, E., Achard, F., Angelsen, A., Xu, J., Lambin, E., 2005. Forest transitions: towards a global understanding of land use change. Glob. Environ. Change 15, 23-31.

Sanz, A.S.R., Fernandez, C., Mouillot, F., Ferrat, L. Istria, D., Pasqualini, V., 2013. Longterm forest dynamics and land-use abandonment in the mediterranean mountains, corsica, France. Ecol. Soc. 18 (2), 38.

Silber, R., Wytrzens, H.K., 2006. Modelling the probability of land abandonment at parcel level. Jahrb. Österreichischen Ges. für Agrar. 15, 55-63.

Sluiter, R., De Jong, S.M., 2007. Spatial patterns of Mediterranean land abandonment and related land cover transitions. Landsc. Ecol. 22, 559-576. 
Song, W., Liu, M., 2014. Assessment of decoupling between rural settlement area and rural population in China. Land Use Policy 39, 331-341.

Song, W., Pijanowski, B.C., 2014. The effects of China's cultivated land balance program on potential land productivity at a national scale. Appl. Geogr. 46, $158-170$.

Strijker, D., 2005. Marginal lands in Europe-causes of decline. Basic Appl. Ecol. 6, 99-106.

Tao Yang, D., 1997. China's land arrangements and rural labor mobility. China Econ. Rev. 8, 101-115.

van Dijk, G., Zdanowicz, A., Blokzijl, R., 2005. Land Abandonment, Biodiversity and the CAP. DLG, Government Service for Land and Water Management of the Netherlands, Utrecht.

van Doorn, A., Bakker, M., 2007. The destination of arable land in a marginal agricultural landscape in South Portugal: an exploration of land use change determinants. Landsc. Ecol. 22, 1073-1087.

Walther, P. 1986. Land abandonment in the Swiss Alps: a new understanding of a land-use problem. Mt. Res. Dev. 6, 305-314.

Wang, X., Herzfeld, T., Glauben, T., 2007. Labor allocation in transition: evidence from Chinese rural households. China Econ. Rev. 18, 287-308.

Weissteiner, C.J., Boschetti, M., Böttcher, K., Carrara, P., Bordogna, G., Brivio, P.A. 2011. Spatial explicit assessment of rural land abandonment in the Mediterranean area. Glob. Planet. Change 79, 20-36.

Woods, M., 2005. Rural Geography: Processes, Responses and Experiences in Rural Restructuring. SAGE, London.

Woods, M., 2012. New directions in rural studies? J. Rural Stud. 28 (1), 1-4.

Zhang, K., Song, S., 2003. Rural-urban migration and urbanization in China: evidence from time-series and cross-section analyses. China Econ. Rev. 14 $386-400$.

Zhang, Y., Li, X., Song, W., 2014. Determinants of cropland abandonment at the parcel, household and village levels in mountain areas of China: a multi-level analysis. Land Use Policy 41, 186-192. 